\title{
SPECIAL TOPIC \\ Legal Regulation of Sodium Consumption to Reduce Chronic Conditions
}

\author{
James G. Hodge Jr, JD, LLM; Leila F. Barraza, JD, MPH
}

\begin{abstract}
Suggested citation for this article: Hodge JG Jr, Barraza LF. Legal Regulation of Sodium Consumption to Reduce Chronic Conditions. Prev Chronic Dis 2016;13:150545. DOI: http:// dx.doi.org/10.5888/pcd13.150545.
\end{abstract}

\section{PEER REVIEWED}

\section{Abstract}

In the United States, tens of thousands of Americans die each year of heart disease, stroke, or other chronic conditions tied to hypertension from long-term overconsumption of sodium compounds. Major strides to lower dietary sodium have been made over decades, but the goal of reducing Americans' daily consumption is elusive. The Food and Drug Administration (FDA) has been urged to consider stronger regulatory limits on sodium, especially in processed and prepared foods. Still, FDA categorizes salt (and many other sodium compounds) as "generally recognized as safe," meaning they can be added to foods when ingested in reasonable amounts. Legal reforms or actions at each level of government offer traditional and new routes to improving chronic disease outcomes. However, using law as a public health tool must be assessed carefully, given potential trade-offs and unproven efficacy.

\section{Introduction}

Sodium is essential to human life, but its overconsumption (primarily through salt) carries substantial public health complications. An estimated 1.65 million deaths from cardiovascular disease globally in 2010 were attributed to excessive sodium intake over time (1). Domestically, tens of thousands of Americans perish each year from heart disease, stroke, or other chronic conditions tied to hypertension (high blood pressure) from long-term overconsumption of sodium compounds (2). Nearly 70 years since its negative public health impact was initially observed in 1948 (3), overconsumption of sodium has become a public health crisis in the United States.
Major strides to lower dietary sodium have been made or attempted over decades (as discussed below), but the goal of reducing Americans' daily consumption is elusive. National calls for broader public health responses have been made repeatedly by academics, doctors, and others (3). The Food and Drug Administration (FDA) has been urged to consider stronger regulatory limits on sodium, especially in processed and prepared foods. To date, FDA still categorizes salt (and many other sodium compounds) as "generally recognized as safe" (GRAS) (4) when ingested in reasonable amounts (3).

Public health and medical officials do not all agree on how much is too much salt. The American Heart Association recommends that daily sodium consumption should not exceed 1,500 mg (5). Federal dietary guidelines suggest limiting sodium intake to no more than 2,300 $\mathrm{mg}$ for individuals aged 14 or older and 1,500 mg for individuals with hypertension or prehypertension (6). An Institute of Medicine panel proposes similarly a Tolerable Upper Intake Limit of 2,300 $\mathrm{mg}$ for persons 14 years or older and average daily intake level of $1,500 \mathrm{mg}$ for persons aged 9 to 51 years (7).

Under any of these standards, Americans' actual sodium consumption is excessive. More than $90 \%$ of American children and close to $90 \%$ of adults ingest salt in excess of the Dietary Guidelines for Americans recommendations (8). Gradual overconsumption is linked to increases in blood pressure because salt can cause the body to retain extra fluids that burden the heart (9). Nearly $30 \%$ of American adults may have hypertension (10), placing them at substantial risk for cardiovascular diseases (which collectively contributed to approximately one-third of US deaths in 2011) (7).

Against this backdrop, we consider actual or potential legal options based on our research and policy assessments to lower the abundance of salt in the food supply substantially. Legal reforms or actions at each level of government offer traditional and new routes to improving chronic disease outcomes. However, using law as a public health tool must be assessed carefully, given unsettled science over the amount of sodium that produces negative health effects, potential legal and policy trade-offs, and unproven costs and efficacy of varied legal interventions. 


\section{Law and Policy Options to Limit Sodium Consumption}

Despite substantial public health repercussions of excessive consumption, regulating sodium intake has historically relied on voluntary efforts designed to encourage consumers to choose healthier foods and food manufacturers, retailers, and servers to provide more healthful options. As a result, consumers are better educated about the risks of sodium and how it is added to foods for flavor, for texture, or as a preservative. Processed food manufacturers and retailers have voluntarily lowered sodium amounts in their products. Schools, restaurants, theaters, and senior-living establishments have reduced sodium in prepared foods through innovative public-private partnerships (11). These and many other efforts show promise in addressing communal health concerns (7), but their impact is piecemeal at best. Average sodium consumption among Americans actually increased 55\% from the mid-1980s to 2000 (12), correlated with a cascade of largely preventable health conditions. Across the United States, public health officials and policy makers are re-examining approaches to limiting the sodium consumption of various populations. These approaches include an increasing array of legal or policy options that entail governmental interventions in the interest of protecting the public's health.

\section{Menu and label warnings}

Most packaged foods have posted sodium content (generally accurate within $20 \%$ of the actual amount as per federal regulation) on their labels since 1986 (7), but similar "on the spot" information about prepared foods is largely absent. FDA's forthcoming menu labeling requirements for restaurants and certain vendors focus largely on caloric posting and not so much on sodium (although such information is available on request) (13). However, FDA's new regulations do not preempt state or local laws requiring menu postings of food warnings, most likely including sodium content. Multiple jurisdictions (eg, California, Oregon, Philadelphia, Seattle-King County) have already implemented menu labeling laws aimed at substantially curbing sodium ingestion. In September 2015, New York City's Board of Health expanded its efforts as part of the 2009 National Salt Reduction Initiative by passing a regulation requiring chain restaurants (with 15 or more locations) to feature sodium warning labels (depicting the image of a saltshaker surrounded by a black triangle) on any menu item containing more than $2,300 \mathrm{mg}$ (14).
New York City's regulations were set to take effect on December 1, 2015, but the National Restaurant Association sued on December 3 challenging the expansion of the city's initiative on constitutional and other grounds (15). Among its claims, the association alleges violations of separation of powers, substantive due process, and freedom of speech principles (to the extent that restauranteurs must post scientifically controversial information about salt content). It also claims that the initiative is preempted by the federal National Labeling and Education Act and generally unauthorized by FDA. Initial hearings have been scheduled, but it will be months before case results are known.

\section{Focus on minors}

Virtually everyone agrees that reducing sodium consumption by minors can improve their life-time health substantially. In 2012, a prominent national theme park operator announced it would reduce sodium levels in children's meals at its parks by $25 \%$ and limit advertising of high sodium products on its media outlets (16). Industry-led voluntary efforts like these are beneficial, but more substantial legal interventions concentrate on cutting sodium in minors' diets at school and in residential childcare institutions. The federal Healthy, Hunger-Free Kids Act of 2010 required numerous changes in sodium levels in children's school lunches and snack foods (17). Schools must reduce the sodium content of meals offered through the National School Lunch Program and the School Breakfast Program by $25 \%$ to $50 \%$ (based on the Institute of Medicine recommendations [7]) by July 1, 2022. New standards also limit snacks sold in school stores, vending machines, or à la carte to $230 \mathrm{mg}$ per item in 2014 and $200 \mathrm{mg}$ by July 1, 2016 (18).

\section{Litigation}

In the fight to lower sodium consumption, litigation may be used to 1) compel greater governmental regulation, 2) require restaurants and other food servers to disclose sodium levels publicly, and 3 ) seek truth in advertising (discussed below). In 2005, the Center for Science in the Public Interest (CSPI) petitioned FDA to reconsider the GRAS classification of sodium, set ceilings on the amount of sodium in processed foods, require health warnings on packaged salt, and reduce the recommended daily intake for sodium (19). CSPI later sued FDA in October 2015, alleging that FDA failed to grant or deny its petition despite holding a hearing on the matter (20).

\footnotetext{
The opinions expressed by authors contributing to this journal do not necessarily reflect the opinions of the U.S. Department of Health and Human Services, the Public Health Service, the Centers for Disease Control and Prevention, or the authors' affiliated institutions.
} 
In 2010, one consumer brought a class action suit in Illinois against a national restaurant chain for its failure to disclose excessive sodium content in certain menu items (21). One of the restaurant's breakfast entrees, for example, purportedly included 5,690 mg of sodium. It was alleged that the company knowingly concealed from consumers information about the excessive amount of sodium in this and other meals. Although the district court dismissed the case for failure to state a claim, extensive media coverage may have contributed to consumer awareness of excessive sodium content in restaurant foods.

\section{Truth in commercial advertising}

Greater public health education of sodium's dangers coupled with pledges from food manufacturers to gradually decrease sodium content in their products have resulted in more "low sodium" products. The Centers for Disease Control and Prevention specifically encourages Americans to use such products pursuant to the federal Dietary Approaches to Stop Hypertension (DASH) initiative (22). In response, manufacturers created products labeled and advertised as "reduced sodium" or "low sodium." Such claims can be made consistent with First Amendment commercial speech principles as long as their statements are not false or misleading.

Assessing the veracity of manufacturers' commercial messages, however, can be dicey given disagreements over the proper benchmarks denoting appropriate or safe limits of sodium (7). Competing terminology can confuse consumers. Labeling canned products as "low sodium," "reduced sodium," or "light sodium" may mean about the same thing to purchasers even though each message denotes appreciably different amounts of sodium via federal guidance. Patently false claims are legally actionable. In 2010, a national soup manufacturer was sued in New Jersey by a class of consumers for allegedly misrepresenting the salt content in its products. Consumers claimed that the company's " $25 \%$ Less Sodium" tomato soup contained the same amount of sodium (480 mg) per serving as its regular tomato soup (23). The company settled the case for $\$ 1.05$ million and agreed to change its labels. Later, in 2013, the same company and the American Heart Association were sued over their dual allowance of "heart healthy" claims for soups with exceptionally high sodium content.

\section{Tax, spend, and ban}

Three public health legal tools often used to deal with products associated with negative public health impacts include 1) taxes (to decrease consumer use and raise public health revenues), 2) spending incentives (to directly influence industry or consumer choices through financial rewards), and 3) bans (to remove a product from the market or limit specific consumers' access) (24). These lawful interventions are used extensively to regulate poten- tially harmful consumables such as tobacco, illicit drugs, alcohol, and even caffeine. On first glance, these powers seem to lack utility regarding sodium - and perhaps for good reason. Unlike other "vice" products, sodium is inexpensive and pervasive in nearly every category of foods and beverages. In small amounts, salt is not only safe but essential. Salt makes food taste better and last longer with no added calories. Taxing or banning salt or other sodium products may seem unjustified, especially considering Americans' common political objections to "nanny state" interventions.

Yet, in reality, each of these regulatory tools applies to sodium already. Salt as an ingredient is not taxed directly via state or local governments, but salty snacks and other foods are. In 2015, the Navajo Nation imposed a $2 \%$ tax on all junk food sold on its reservation, including an array of high sodium products of "minimalto-no nutritional value." (24) Kentucky, Texas, Washington, and other jurisdictions exempt junk foods from tax-free policies applicable to fresh produce, dairy products, and other healthful food choices. In both examples, the brunt of these tax schemes falls hard on products with elevated sodium content. Less clear is whether these taxes are substantial enough to influence consumers away from high salt foods (as has been shown by the substantial tax imposed on sugar-sweetened beverages in Mexico) (25). Spending policies underlying federal and state implementation of food stamp programs encourage recipients to purchase fresh fruits, vegetables, and dairy products but not processed junk foods, which are often loaded with sodium.

Banning sodium in all processed foods is impossible, but partial bans may be viable legally. Limiting or banning access to salty products for minors at school, as discussed above, is lawful just the same as bans on selling tobacco, alcohol, or sugar-sweetened beverages. Prohibiting overuse of sodium as a flavor or preservative in specific products (eg, infant formula) for certain populations (eg, babies) may be legally defensible provided government can demonstrate legitimate, correlated public health concerns.

\section{Conclusion}

Substantially lowering Americans' sodium consumption requires a multifaceted, public-private strategy that considers legal interventions in tandem with other public health interventions designed to reduce sodium intake through processed and served foods. As with successful voluntary measures, legal steps to curb sodium consumption may have to proceed slowly or in stages to circumvent negative industry or public reactions. Specific legal strategies such as enhanced consumer warnings, litigation, taxation, or partial bans may need to be proven efficacious to sustain their continued or increased use. Some legal interventions may work better than

The opinions expressed by authors contributing to this journal do not necessarily reflect the opinions of the U.S. Department of Health and Human Services, the Public Health Service, the Centers for Disease Control and Prevention, or the authors' affiliated institutions. 
others, at lower cost, and with fewer trade-offs. If the end goal is to reduce Americans' sodium consumption over time to reduce chronic conditions, efficacious and cost-efficient legal interventions are an essential component of a concerted national plan.

\section{Acknowledgments}

We have no conflicts of interest to declare. We acknowledge the contributions of Kim Weidenaar, JD, Alicia Corbett, JD, Brenna Carpenter, Sarah Wetter, and Matt Saria of Arizona State University's Public Health Law and Policy Program for their research, editing, and formatting assistance.

\section{Author Information}

Corresponding Author: James G. Hodge, Jr, Professor and Director, Public Health Law and Policy Program, Western Region Office, Network for Public Health Law, Sandra Day O'Connor College of Law, Arizona State University, 1100 S McAlister Ave, Tempe, AZ 85287-7906. Telephone: 480-727-8576. Email: james.hodge.1@asu.edu.

Author Affiliations: Leila F. Barraza, University of Arizona, Tucson, Arizona.

\section{References}

1. Mozaffarian D, Fahimi S, Singh GM, Micha R, Khatibzadeh S, Engell RE, et al.;Global Burden of Diseases Nutrition and Chronic Diseases Expert Group. Global sodium consumption and death from cardiovascular causes. N Engl J Med 2014; 371(7):624-34.

2. Severson K. Throwing the book at salt. New York Times 2009January 27. http://www.nytimes.com/2009/01/28/travel/ 28iht-28salt.19735750.html?_r=0. Accessed January 6, 2016.

3. Kempner W. Treatment of kidney disease and hypertensive vascular disease with rice diet. J Am Med Assoc 1948; 4:544-7.

4. Food and Drug Administration. Lowering salt in your diet. http://www.fda.gov/ForConsumers/ConsumerUpdates/ ucm181577.htm. Accessed October 29, 2015.

5. Appel LJ, Frohlich ED, Hall JE, Pearson TA, Sacco RL, Seals DR, et al. The importance of population-wide sodium reduction as a means to prevent cardiovascular disease and stroke: a call to action from the American Heart Association. Circulation 2011;123(10):1138-43. http://circ.ahajournals.org/ content/early/2011/01/13/CIR.0b013e31820d0793.full.pdf. Accessed January 6, 2016.
6. Dietary guidelines for Americans, 2015-2020. 8th edition. Washington (DC): US Department of Agriculture, US Department of Health and Human Services; 2015. http:// health.gov/dietaryguidelines/2015/guidelines. Accessed January 6, 2016.

7. Institute of Medicine. Sodium intake in populations: assessment of evidence. Washington (DC): National Academies Press; 2013.

8. Jackson SL, King SM, Zhao L, Cogswell ME. Prevalence of excess sodium intake in the United States - NHANES, 2009-2012. MMWR Morb Mortal Wkly Rep 2016; 64(52):1393-7.

9. Farquhar WB, Edwards DG, Jurkovitz CT, Weintraub WS. Dietary sodium and health: more than just blood pressure. J Am Coll Cardiol 2015;65(10):1042-50.

10. Nwankwo T, Yoon SS, Burt V, Gu Q. Hypertension among adults in the United States: National Health and Nutrition Examination Survey, 2011-2012. NCHS Data Brief 2013; 133(133):1-8.

11. Sodium Reduction in Communities Program (SRCP). Atlanta (GA): US Department of Health and Human Services, Centers for Disease Control and Prevention, National Center for Chronic Disease Prevention and Health Promotion, Division for Heart Disease and Stroke Prevention; 2015. http:// www.cdc.gov/dhdsp/programs/sodium_reduction.htm. Accessed January 6, 2016.

12. Karppanen H, Mervaala E. Sodium intake and hypertension. Prog Cardiovasc Dis 2006;49(2):59-75.

13. Menu and vending machines labeling requirements. Washington (DC): US Department of Health and Human Services, Food and Drug Administration; 2015. http:// www.fda.gov/Food/Ingredients PackagingLabeling/ LabelingNutrition/ucm217762.htm. Accessed January 6, 2016.

14. Mueller B, Grynbaum MM. New York City health board backs warning on menu items with high salt. New York Times. 2015September 9. http://www.nytimes.com/2015/09/10/ nyregion/new-york-city-health-board-approves-sodiumwarnings-on-menus.html. Accessed January 6, 2016.

15. Verified Article 78 \& Declaratory Judgement Petition, National Restaurant Association v. New York Department of Health and Mental Hygiene et al. N.Y. Sup. (No. 654024) (2015).

16. Barnes B. Promoting nutrition, Disney to restrict junk-food ads. New York Times. 2010June 5. http://www.nytimes.com/ 2012/06/05/business/media/in-nutrition-initiative-disney-torestrict-advertising.html? r=1. Accessed January 6, 2016.

17. Healthy, Hunger-Free Kids Act of 2010, P.L. 111-296 ( 2010).

18. Nutrition Standards for All Food Sold, 78 Fed. Reg. 39068, 39069.

\footnotetext{
The opinions expressed by authors contributing to this journal do not necessarily reflect the opinions of the U.S. Department of Health and Human Services, the Public Health Service, the Centers for Disease Control and Prevention, or the authors' affiliated institutions.
} 
19. Petition to revoke the GRAS status of salt, to set ceilings on the amount of sodium in processed foods, to require a health warning on packaged salt, and to reduce the daily value for sodium. Washington (DC): Center for Science in the Public Interest; 2005. https://www.cspinet.org/new/pdf/ fda_salt_petition.pdf. Accessed January 6, 2016.

20. Center for Science in the Public Interest v. US Food and Drug Administration, No. 15-1651 (D.D.C., filed October 8, 2015). http://cspinet.org/new/pdf/sodium-complaint-final-10-8-15.pdf. Accessed January 6, 2016.

21. Ciszewski v. Denny’s Corp., 2010 WL 2220584 (N.D. Ill. 2010).

22. How to reduce sodium. Atlanta (GA): US Department of Health and Human Services, Centers for Disease Control and Prevention, National Center for Chronic Disease Prevention and Health Promotion, Division for Heart Disease and Stroke Prevention; 2014 , http://www.cdc.gov/salt/ reduce_sodium_tips.htm. Accessed November 5, 2015.

23. Smajlaj v. Campbell Soup Co., No. 10-01332 (U.S. Dist. Ct., D.N.J., preliminary approval granted August 9, 2011).

24. Hodge J.Public health law in a nutshell. 2nd edition. St Paul, (MN): West Academic Publishing; 2016.

25. Colchero MA, Popkin BM, Rivera JA, Ng SW. Beverage purchases from stores in Mexico under the excise tax on sugar sweetened beverages: observational study. BMJ 2016; 352:h6704.

The opinions expressed by authors contributing to this journal do not necessarily reflect the opinions of the U.S. Department of Health and Human Services, the Public Health Service, the Centers for Disease Control and Prevention, or the authors' affiliated institutions. 